Strazicich, M.C. (1997). Does Tax Smoothing Differ by the Level of Government? Time Series Evidence from Canada and the United States. Journal of Macroeconomics, 19(2): 305-326 (April 1997). Published by Elsevier (ISSN:

0164-0704). http://0-dx.doi.org.wncln.wncln.org/10.1016/S0164-0704(97)00017-7

\title{
Does Tax Smoothing Differ by the Level of Government? Time Series Evidence from Canada and the United States
}

Mark C. Strazicich

\begin{abstract}
The tax smoothing theory is examined for Canada and the United States. A distinction is made between federal and local levels of government. Mobility of taxable resources at the state and local levels may constrain the ability of these governments to smooth tax rates. Testing is undertaken in the frequency domain to see if the cumulated periodogram of the first differenced tax rate series differs from white noise. Testing is undertaken with and without correction for time averaging. Results generally support tax smoothing by both federal governments and the Canadian provinces. Tax smoothing is rejected for state and local governments.
\end{abstract}




\section{INTRODUCTION}

This study examines the tax-smoothing hypothesis in Canada and the United States at both federal and local levels of government. Tax smoothing implies that the tax rate behaves as a random walk. Testing is undertaken in the frequency domain to see if the cumulated periodogram of the first differenced tax rate series differs from white noise. The methodology was suggested in Bizer and Durlauf (1990). Testing is undertaken with and without correction for time averaging. Results generally support tax smoothing by both federal governments and the Canadian provinces. Tax smoothing is rejected for state and local governments. Resource mobility is suggested as an explanation for the tax smoothing differences.

Section 2 looks at the theory of efficient taxation over time. A distinction is made between national and state and local governments. Section 3 presents the model. Section 4 looks at the historical time series data on budget surpluses. Section 5 discusses the tax rate data. Section 6 examines two cumulated periodogram statistics to see if the first differenced tax rate series rejects white noise. Correction is made for using time averaged tax rates by filtering the data. In addition, regression tests are performed for federal tax rates. Section 7 summarizes the results.

\section{EFFICIENT TAXATION OVER TIME}

Tax smoothing results when governments set tax rates so as to minimize the costs of taxation over time. Given the long-run constraint of a balanced budget, if the marginal costs of taxation are an increasing function of the amount of resources taxed (i.e., the "tax rate"), then minimization of the total costs of taxation implies that the planned tax rate will be constant over time. Changes in tax rates will be unpredictable, and the tax rate will behave as a random walk. Deviations in government spending and output from their permanent levels results in deficits and surpluses. Therefore, tax smoothing provides a theory of government debt. The model is primarily due to Barro (1979).

Empirical testing of the tax-smoothing hypothesis has focused on federal tax rates. Sahasakul (1986) examines a regression model of the U.S. federal tax rate based on Barro. Sahasakul rejects tax smoothing due to the significance of temporary government spending. A potential problem with Sahasakul's test arises from the need to separate government spending into permanent and temporary components. One cannot tell if rejection of tax smoothing is due to a failure of government to smooth tax rates or an unreliable forecasting equation for government spending. Bizer and Durlauf $(1990,1991)$ examine the random walk implication directly. Time series analysis in the frequency domain is employed to see if the first differenced tax rate series rejects randomness, or white noise. This methodology avoids the need to estimate temporary and permanent government spending variables. Bizer and Durlauf, in general, reject the white noise hypothesis for U.S. 
federal tax rates. Barro (1981, 1986), Kochin, Benjamin, and Meador (1986), and Huang and Lin (1993) find general support for tax smoothing by the U.S. federal government. Trehan and Walsh (1988) reject tax smoothing by the U.S. federal government. Gupta (1992) finds evidence favoring tax smoothing by the Canadian federal government. Horrigan (1986) is an exception to the focus on only federal tax rates. Using quarterly data, Horrigan finds general support for Barro's tax smoothing model when examining U.S. federal debt but rejects tax smoothing when examining U.S. state and local debt. 1

Benjamin and Kochin $(1978,1982)$ suggest the ability of governments to smooth tax rates may be restricted by the mobility of taxable resources. At the state and local levels, as temporary deficits and surpluses occur, mobile resources could seek out jurisdictions where the current benefits of government spending exceed the current costs. Therefore, state and local governments may be prevented from engaging in tax smoothing. This could explain the large number of balanced budget rules that exist among state and local governments in the U.S. Nearly every state government in the U.S. has a balanced budget rule. Mobility predicts such rules.

Compared to the U.S., Canada's provinces are generally larger in area than most states. With two official languages in use, and French being confined largely to Quebec, there may be less mobility of human resources in Canada.2 Contrary to the states, no balanced budget rules exist for the Canadian provinces. Canadian local governments are restricted in the amount of debt they may issue, as all local debt proposals must be approved by the province.

This study extends the work of Bizer and Durlauf primarily in two ways. First, the methodology is applied to Canada. Second, the methodology is used to see if tax smoothing differs by the level of government.

\section{THE MODEL}

The model assumes a government budget identity in period $t$ as follows:

$$
\tau_{t} Y_{t}+\left(B_{t}-B_{t-1}\right) \equiv G_{t}+r B_{t-1}
$$

where $G t$ is real total government expenditures, excluding interest on the public debt, $r$ is the real rate of interest, and $B t$ is the real stock of public debt outstanding at the end of time period $t$. $Y t$ is real output, and $s t$ is the "tax rate." stYt equals real total tax revenue collected at time $t$, or Tt. After dividing terms in Equation (1) by real output, an intertemporal budget constraint can be derived as follows:

$$
\sum_{j=0}^{\infty}(1+\rho)^{-j} E \tau_{t+j}=\sum_{j=0}^{\infty}(1+\rho)^{-j} E g_{t+j}+(1+\rho) b_{t-1},
$$


where $E$ is the expectation operator, $g_{t} \equiv G_{t} / Y_{t}, \tau_{t} \equiv T_{t} / Y_{t}, b_{t} \equiv B_{t} / Y_{t^{*}} \rho$ is the real rate of interest minus the growth rate of real output and is assumed to be constant over time.

The model assumes the marginal cost, or marginal excess burden, of tax collection is an increasing function of $\tau_{t}$. Total costs of taxation are assumed to increase quadratically with $\tau_{t}$, and the marginal excess burden function is assumed to be invariant over time. Government spending is assumed to be exogenously determined. As shown in Barro (1979), minimization of the present value of the total cost of taxation over time, subject to the intertemporal budget constraint, implies equality of $\tau_{t}$ over time. Sahasakul shows that after substituting $E \tau_{t+1}=\tau_{t}$ for all $j \neq 0$ in (2), Equation (3) can be derived as follows:

$$
\tau_{t}=\bar{g}_{t}+\rho b_{t-1}
$$

where $\bar{g}_{t}$ is the permanent expenditures to output ratio at time $t$, and $\rho b_{t-1}$ equals debt interest payments net of the real output growth rate times the ratio of outstanding real public debt to output at the end of period $t-1$. $\bar{g}_{t}$ is equivalent to an annuity value of present and expected future government spending relative to output, similar to the measurement of permanent income. Equation (3) shows that only the ratio of permanent government spending to output and the stock of previously outstanding government debt to output determines the tax rate at $t$. Temporary changes in spending or output result in temporary deficits or surpluses, with no change in $\tau_{t}$.

Given information today about the future path of spending and output, the tax rate $\tau_{t}$ is expected to remain unchanged. Today's tax rate is an unbiased predictor of future tax rates. This condition can be described as follows:

$$
E\left(\tau_{t+j} \mid I_{t}\right)=\tau_{t}
$$

where $I_{t}$ is the information relevant to tax smoothing available at time $t$. Equation (4) implies that the tax rate behaves as a random walk. The random walk condition can be described as follows:

$$
\Delta \tau_{t}=\mu+\varepsilon_{t}, \quad \varepsilon_{t} \sim\left(0, \sigma^{2}\right),
$$

and

$$
E\left(\varepsilon_{t} \varepsilon_{t-j}\right)=0 \quad j \neq 0,
$$


where $\Delta \tau_{t}=\tau_{t}-\tau_{t-1}, \mu$ is a constant term or "drift," and $\varepsilon_{t}$ is a white noise error term that is independent and identically distributed. Tax smoothing may or may not exhibit a drift in tax rates. A constant marginal cost function for tax rates over time implies that $\mu=0$. The random walk hypothesis implies that none of the autocorrelations in the residuals from the first differenced tax rate is significantly different from zero.

\section{BUDGET SURPLUS TIME SERIES}

This section examines the historical time series data on budget surpluses in Canada and the U.S. at all levels of government. The historical data suggest that both federal governments and the Canadian provinces smooth tax rates but that state and local governments do not.

When examining deficits for evidence of tax smoothing, a more valid measure of debt to examine at the state/provincial and local levels would be debt incurred from current, or non-capital, expenditures. Resource mobility would limit state/provincial and local governments in their means of finance. If large capital projects were financed with current taxes, mobile resources could move into the area after the tax was paid by the current residents. The mobile resources could then realize the benefits of capital spending without bearing the costs. With mobility, state/provincial and local levels of government would be expected to finance capital expenditures with debt. Therefore, capital expenditures will be excluded from measures of provincial/state and local government deficits shown below.

Figure 1 shows a comparison of federal government budget surplus ratios. The behavior of deficits and surpluses is similar in both countries. The Depression years of the 1930s have mostly budget deficits. The World War II years are characterized by large deficits followed by surpluses afterwards. The recessions of 1975 and 1982 show marked increases in relative deficits. The large post-1983 deficits appear unusual and imply future budget surpluses under tax smoothing. Overall, Figure 1 suggests that both countries are likely engaged in tax smoothing at the federal level.

Figures 2 and 3 show aggregate current budget surplus ratios for state, provincial, and local governments. U.S. state and local budget surplus ratios are shown with and without their social insurance fund surplus. The social insurance surplus, incurred primarily from pension funds of government workers, can distort the overall budget surplus data. It appears that state and local governments are not tax smoothing. Their budgets remain relatively stable and at a surplus, with or without the social insurance fund. Contrary to this, examination suggests the Canadian provinces may be tax smoothing. We see more variation in provincial surpluses and deficits. Both Canada and the U.S. experienced recessions in 1975 and 1982, but only the Canadian provinces realized deficits for these years. State and local government budget surpluses remained relatively unchanged. The above suggests that provincial governments are more likely engaged in tax smoothing than state and local 
governments.3

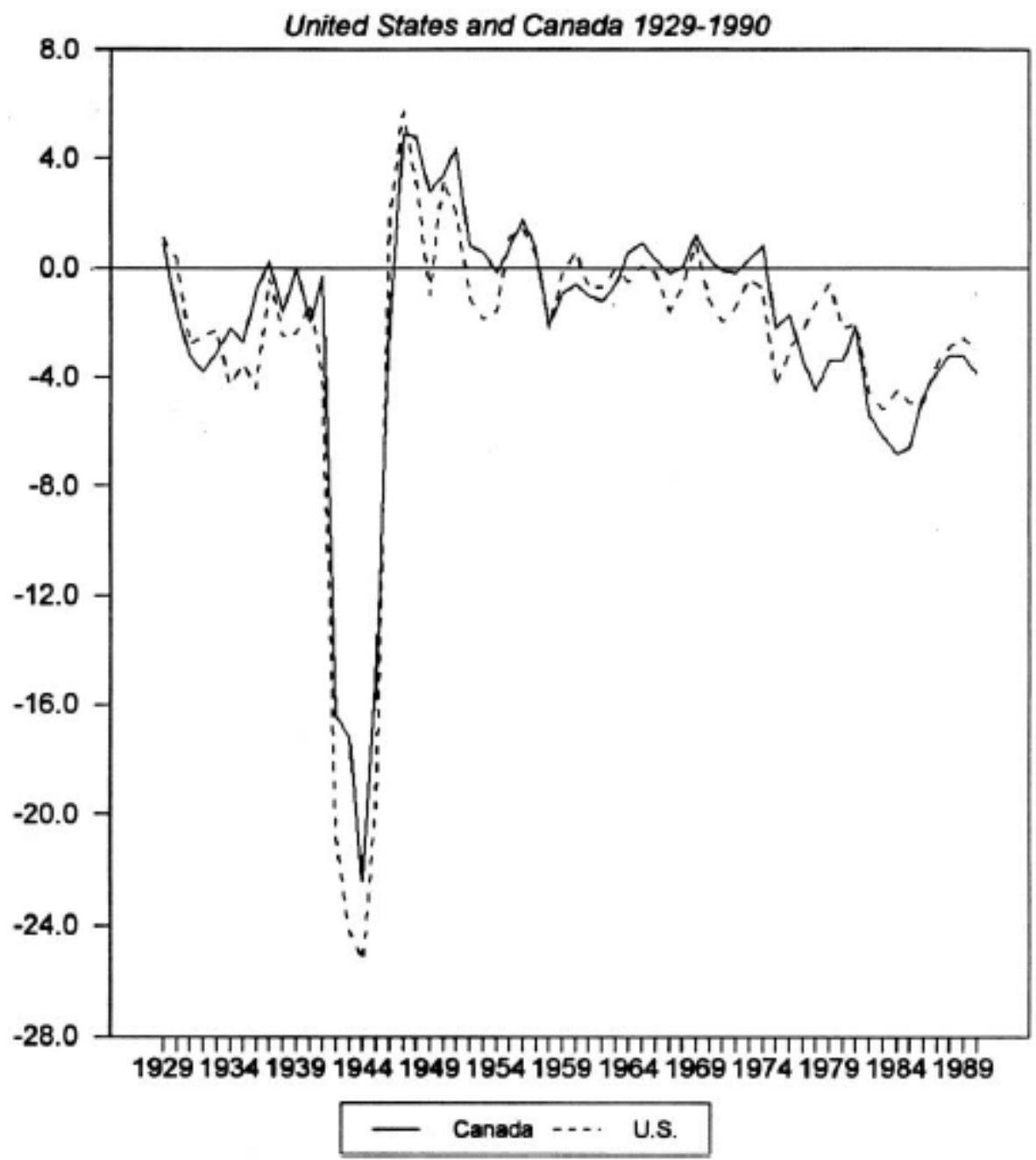

Figure 1.

Federal Budget Surplus Ratios

Note: Comparison of federal government total budget surpluses as a percentage of GDP in Canada and GNP in the U.S. See Appendix for data source. 


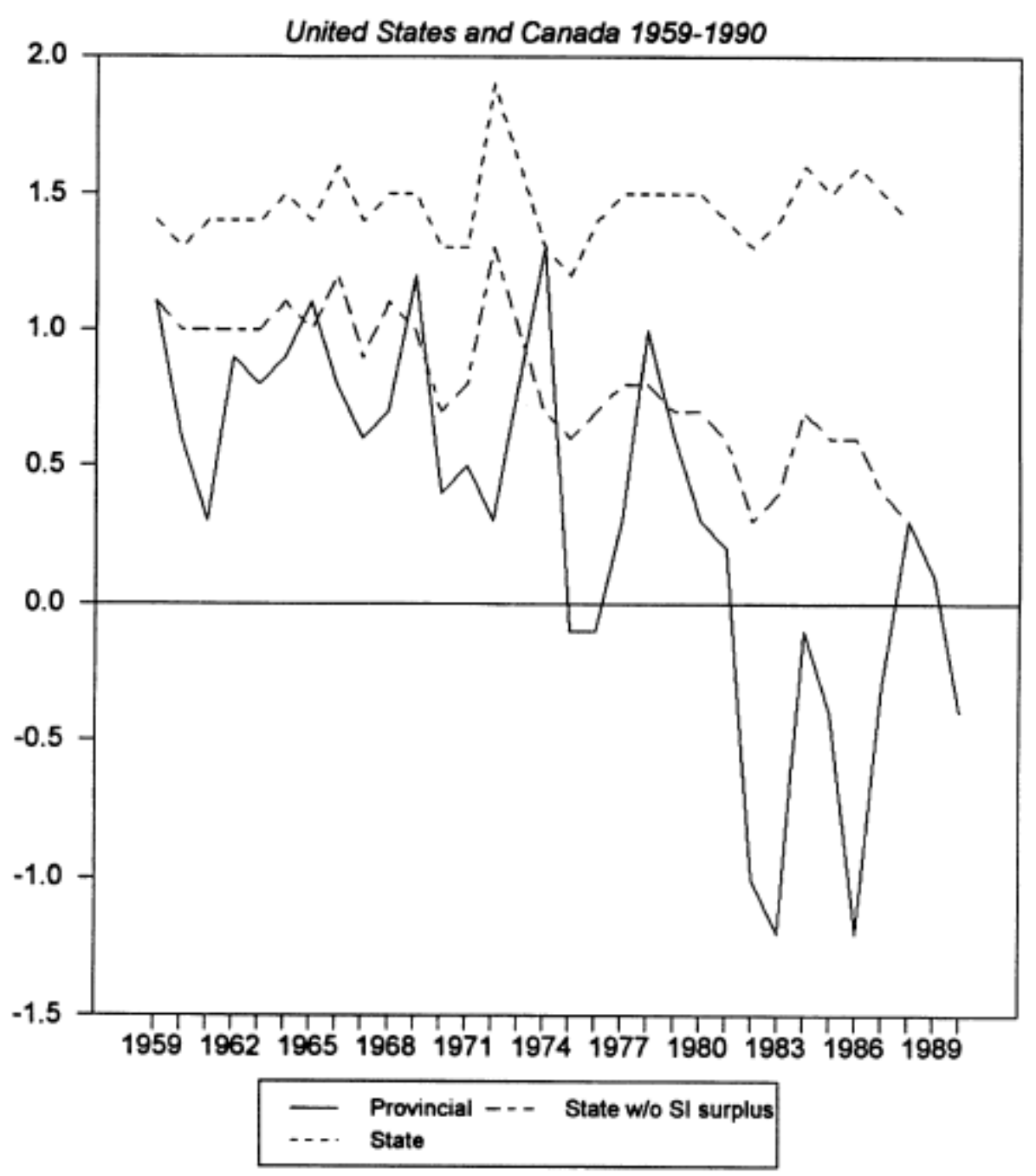

Figure 2.

State and Provincial Budget Surplus Ratios

Note: Comparison of provincial and state government current budget surpluses as a percentage of GDP in Canada and GNP in the U.S. Current budget surplus measures are without capital expenditures. U.S. figures are shown with and without the social insurance fund surplus (SI). See Appendix for data source. 


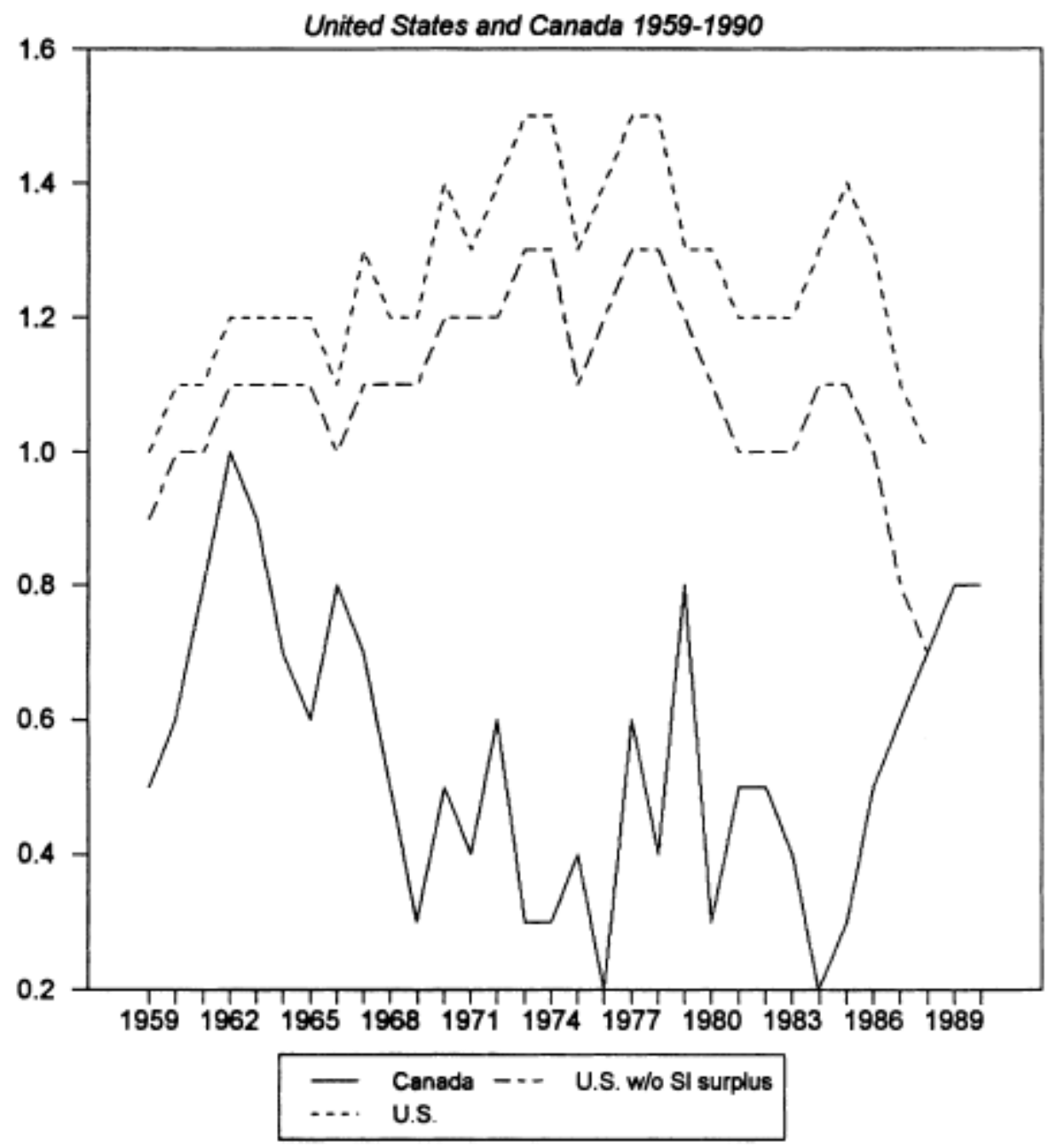

Figure 3.

Local Budget Surplus Ratios

Note: Comparison of local government current budget surpluses as a percentage of GDP in

Canada and GNP in the U.S. Current budget surplus measures are without capital expenditures. U.S. figures are shown with and without the social insurance fund surplus (SI).

See Appendix for data source.

\section{TAX RATE DATA}

The average or proportional tax rate series will be examined in both Canada and the U.S. at each level of government. The average tax rate is calculated as total tax revenue divided by GDP for Canada and by GNP for the U.S. To compare the results here with those of others, the "marginal tax rate" will also be examined at the federal levels.

Some revenue collected by governments may be considered as nontax revenue. Such revenue could occur if government sells, rents, or leases any assets it owns. This revenue is not a tax per se, since people are paying for the use of a government owned asset. Government transfer revenue to the 
provincial/state and local governments is also a type of nontax revenue. There is no reason why tax-smoothing behavior should occur for nontax revenue; therefore, to examine the tax smoothing hypothesis more accurately, nontax revenue will be subtracted from total revenue when feasible.

A consistent time series of separate U.S. state and local taxes and output is unavailable before 1959. Therefore, the 1929-1990 combined series will be employed for testing. There is some question as to the inclusion of social insurance collections in tax receipts. The key point is whether incremental social insurance revenue collected by the government can be considered a tax. Boskin and Puffert (1987) simulate the net benefits from social insurance contributions for various groups in the U.S. and find that for a large part of working households the incremental benefit is less than the incremental tax. For some individuals, social insurance contributions can be considered a pure tax. Rea (1981) finds that large segments of the Canadian working population can expect to receive little extra benefits from their Canada Pension Plan and Quebec Pension Plan contributions. The above studies provide evidence to suggest that social insurance revenue can be considered largely as a tax. Therefore, this study will include social insurance collections in all measures of total tax receipts. 4

The theory of optimal taxation over time is really a theory concerned with equalizing marginal excess burdens over time. A marginal cost of taxation function which is constant over time implies a uniform marginal rate of taxation over time. Sahasakul and Gupta test models using estimates of the "marginal tax rate" for the U.S. and Canadian federal governments respectively. Except for the income tax, most taxes can be described as average or proportional. Which tax rate is preferable in empirical testing? First, the "marginal tax rates" employed by Sahasakul and Gupta are calculated as averages of marginal income tax rates, in addition to other, proportional, taxes. Second, tax deductions can change at the margin. Marginal changes in income tax deductions are not included in the average marginal tax rate but are included in the average tax rate. Therefore, it is not clear which measure of the tax rate is preferable for testing. For comparison, both average and "marginal tax rates" will be examined at the federal levels. 5

\section{TIME SERIES ANALYSIS}

Time series analysis in the frequency domain is undertaken for the first differenced tax rate to test for significant departure from white noise. Tax smoothing implies that the first differenced tax rate resembles a white noise process. Two cumulated periodogram statistics are estimated to see if the shape of the sample spectral distribution function differs from white noise. This approach was suggested in Bizer and Durlauf (1990). Correction for the use of first differenced averages is made by filtering the data. Regression tests are also performed for federal tax rates. Results generally support tax smoothing by both federal governments and the Canadian provinces but reject tax smoothing by state and local governments. 
The theoretical spectral density $f(\lambda)$ of a white noise process is equal at all frequencies and can be described as follows:

$$
f(\lambda)=\sigma^{2} / 2 \pi
$$

where $k$ is the frequency of the cycle, and $\sigma^{2}$ is the variance of the first differenced time series. Estimates of the spectral density at a particular frequency have been shown to give results that are unbiased but not consistent. 6 As well, even if the sample is truly random, occasional large random deviations, or cycles, could show up as a significant spike in the spectral density. A cumulated periodogram test was suggested as a test of the martingale hypothesis in Bizer and Durlauf. Contrary to the spectral density at individual frequencies, the cumulated deviations of the white noise spectral density converge to zero (e.g., Durlauf 1991). Since the cumulated periodogram test examines all frequencies, the test is valid for all implications of the white noise null hypothesis and is equivalent to examining all autocorrelations in the time domain.

Under the white noise null hypothesis, the shape of the spectral density would be a rectangle, implying that the spectral distribution function is shaped as a diagonal line. Rejection of the null hypothesis implies that the cumulated deviations from the white noise diagonal are too large to be considered sampling error. Two cumulated periodogram "goodness-of-fit" statistics are examined here: the Cramer-von Mises statistic and the Kolmogorov-Smirnov statistic. 7

A potential problem with estimating the autocorrelations of a first differenced time series has been noted in Working (1960). If averages are constructed from sets of random numbers, the autocorrelations of the first differences will give misleading results. ut will be a first-order moving average as follows:

and

$$
\Delta \tau_{t}=u_{t}=e_{t}+\theta e_{t-1}, \quad e_{t} \sim\left(0, \sigma_{e}^{2}\right)
$$

Given the above, the correlation between ut and ut_1 would be as follows:

$$
E\left(e_{t} e_{t-j}\right)=0, j \neq 0 \text {. }
$$

where $n$ is the number of observations in each average. The first-order autocorrelation coefficient of $u_{t}$ equals 0.25 as $n$ approaches infinity. 8

How important might the time averaging effect be? In a world of zero costs, tax smoothing could imply continuous smoothing as new information about the future path of permanent government spending and output became available. Since major tax rate changes entail significant costs, such changes generally occur not more than once a year. In some years a major 
tax rate change has occurred twice. 9 Therefore, the proper correction for time averaging appears to be either no correction at all or a correction for two tax rate changes per year.

Correction for time averaging can be made by employing a filter on the first differenced tax rate series. The correct filter is a forward filter using the partial correlations of the theoretical first differenced series. This filter was suggested in Hayashi and Sims (1983). 10 Given two random sequences in each average, or $n_{2} 2$ in Equation (8), the theoretical autocorrelation coefficient of the first differenced series at lag one would be 0.167 . The filter would be as follows:

$$
\Delta \tau_{t}^{\prime}=\Delta \tau_{t}-0.172 \Delta \tau_{t+1}+0.030 \Delta \tau_{t+2}-0.005 \Delta \tau_{t+3},
$$

where the infinite autoregressive process is approximated by the terms to $t$ $+3.11$

The Cramer-von Mises and the Kolmogorov-Smirnov cumulated periodogram statistics were estimated as follows. Results are shown in Table 1, with and without correction for time averaging given two tax rate changes per year.

TABLE 1. Periodogram-Based Tests of White Noise

\begin{tabular}{llllll}
\hline \multicolumn{5}{c}{ First Differenced Tax Rate } \\
\hline & \multicolumn{7}{c}{ CVM } & \multicolumn{1}{c}{ KS } & CVM & KS \\
\hline United States & & & & & \\
$\quad$ Federal (average) & $1930-1990$ & 0.30 & 1.06 & 0.05 & 0.40 \\
Federal (marginal) & $1939-1982$ & $1.10^{* *}$ & $1.73^{* *}$ & $0.66^{*}$ & $1.45^{*}$ \\
$\quad$ State and Local & $1930-1990$ & $1.62^{* *}$ & $2.21^{* *}$ & $0.89^{* *}$ & $1.81^{* *}$ \\
Canada & & & & & \\
Federal (average) & $1927-1990$ & $0.88^{* *}$ & $1.72^{* *}$ & 0.38 & 1.17 \\
Federal (marginal) & $1948-1984$ & 0.28 & 1.02 & $0.84^{* *}$ & $1.58^{*}$ \\
Provincial & $1927-1990$ & $0.73^{*}$ & 1.30 & 0.37 & 0.96 \\
Local & $1927-1990$ & $2.46^{* *}$ & $2.58^{* *}$ & $1.70^{* *}$ & $2.08^{* *}$ \\
$5 \%$ critical value & & 0.46 & 1.36 & 0.46 & 1.36 \\
$1 \%$ critical value & & 0.74 & 1.64 & 0.74 & 1.64 \\
\hline
\end{tabular}

NOTE: Variable tested is the first differenced average tax rate except at the federal level, where both average and marginal tax rate measures are tested. CVM and KS denotes estimated values of the Cramer-von Mises and the Kolmogorov-Smimov statistics respectively. CVM and KS are scalar random cumulated periodogram statistics that test for deviations in the estimated periodogram from the null hypothesis of white noise. CVM $\mathrm{W}_{\mathrm{w}}$ and $\mathrm{KS}_{\mathrm{w}}$ denote estimated values of the Cramer-von Mises and the Kolmogorov-Smirnov statistics respectively, after correcting for time averaging. Correction for time averaging was made by filtering the first differenced tax rate series for two tax rate changes per year, as described in Equation (9). See Appendix for data source.

*Significant at asymptotic 5\% level. **Significant at asymptotic $1 \%$ level. 
Average tax rate results support tax smoothing by the U.S. federal government. The Canadian federal and provincial results are sensitive to adjustment for time averaging. After correction for time averaging, results support tax smoothing. Results clearly reject tax smoothing by state and local governments. The strongest rejection is at the local level.

The U.S. federal average tax rate results differ from those reported in Bizer and Durlauf. The difference is due to the data in the samples tested. Bizer and Durlauf reject the random walk implication using average tax rate data for the periods 1879-1986 and 1879-1945.12 The 1929-1990 sample period used in this study may be more appropriate for testing the tax smoothing hypothesis because tax receipts are measured on an accrual basis. Tax receipts were measured on a cash basis only prior to 1929.

The federal "marginal tax rate" results are less favorable towards tax smoothing. U.S. federal government results reject tax smoothing, with or without adjustment for time averaging. The Canadian federal government results are sensitive to adjustment for time averaging. Before adjustment, the Canadian results are unable to reject tax smoothing. After adjusting for time averaging, the Canadian results reject tax smoothing. As noted earlier, it is not clear whether the average or "marginal tax rate" measure is preferred for testing. Therefore, the above results do not provide a clear answer to the question of whether or not federal tax rates reject tax smoothing.

To examine federal tax rates further, regression tests were undertaken to see if tax rate changes are unpredictable. Tax smoothing implies that tax rate changes will be unpredictable from past information. First differenced federal average and marginal tax rates were regressed on their own lagged values, lagged ratios of government spending to output, and lagged real output growth. Lags of one to four years were employed. Testing was undertaken with and without correction for time averaging. Filtered variables were used as described in Equation (9) for the first differenced tax rate, given two tax rate changes per year. Other variables were adjusted with a similar filter, except where $n$ approaches infinity. Instrumental variables were employed as suggested in Hayashi and Sims. As an additional test, time averaging was also corrected by omitting the lag-one variables. This method of correcting for time averaging was suggested in Barro (1981). Results are shown in Table 2. For federal average tax rates, only two out of twelve lagged variables were significant for each country, at the $5 \%$ level. For federal marginal tax rates, no lagged variables were significant in the U.S. case, while only two out of twelve lagged variables were significant for Canada, at the $5 \%$ level. After adjusting for time averaging by filtering the data, no lagged variables were significant at the $5 \%$ level for either tax rate in Canada or the U.S. After adjusting for time averaging by omitting lag-one variables, only one variable was significant at the $5 \%$ level for each tax rate measure in Canada. No variables were significant for the U.S. An advantage of the above tests is the lack of necessity to separate permanent from temporary government spending. The Canadian results generally support those of Gupta, which could not reject tax smoothing using federal marginal tax rates. The U.S. results are opposite to those reached by Sahasakul. The difference may 
be due to the difficulties involved in separating permanent from temporary government spending in Sahasakul's test.13

TABLE 2. Federal First Differenced Tax Rate Tests of Lagged Information
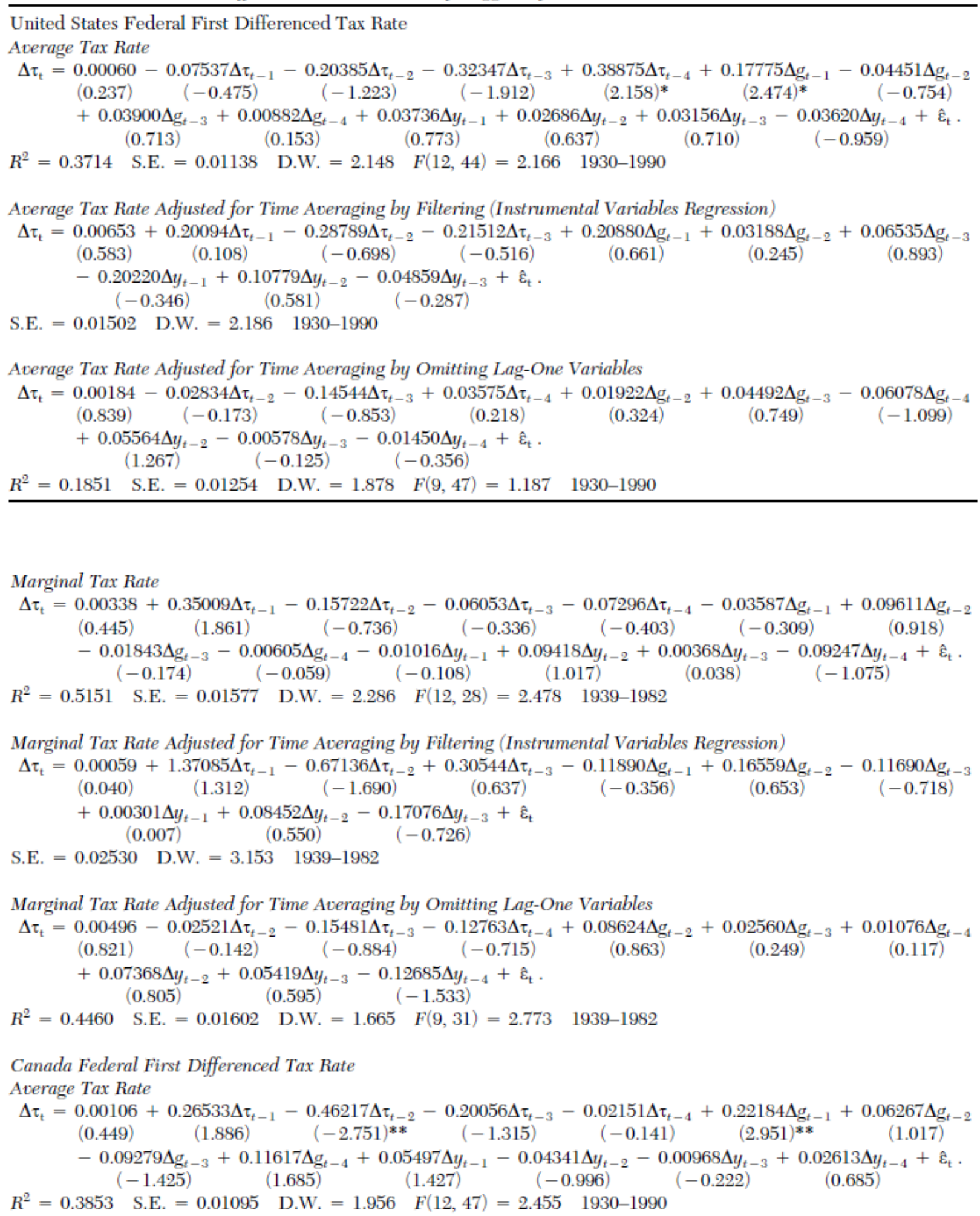
TABLE 2. Continued

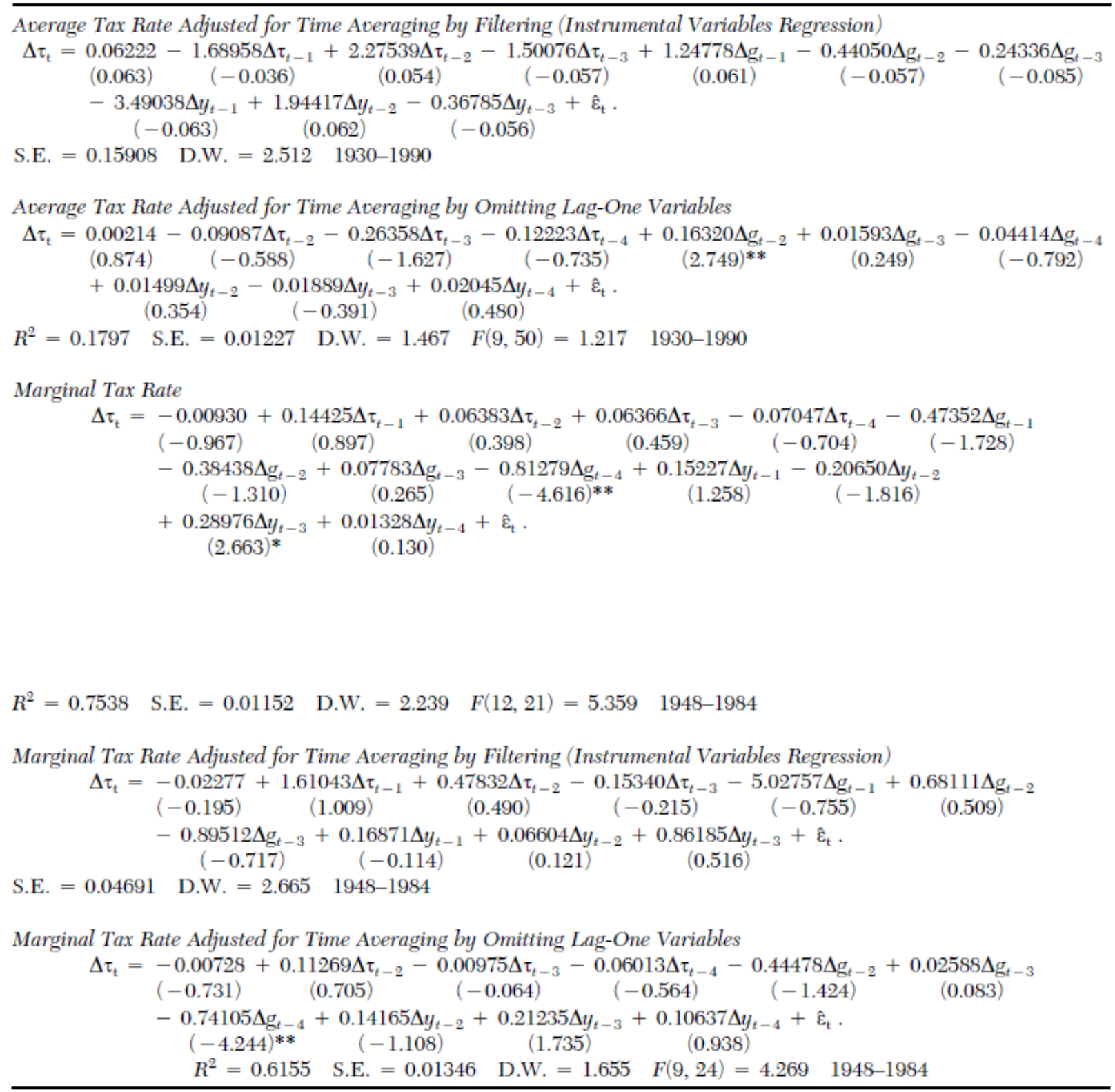

NOTES: $\Delta \tau_{\mathrm{t}}$ and $\Delta \mathrm{g}_{\mathrm{t}}$ are the first differenced tax rate and government spending to output ratios, and $\Delta y_{\mathrm{t}}$ is the growth of output. $\varepsilon_{\mathrm{t}}$ is the residual. $t$-statistics are shown in parentheses. ${ }^{* *}$ Significant at the $1 \%$ level. *Significant at the $5 \%$ level.

Data aggregated from all provinces, states, or local governments were used in the tests reported in Table 1. If these governments are not tax smoothing, but adjusting tax rates each period in response to current conditions, it is possible that aggregating data from all provinces, states, or local governments could give the appearance of tax smoothing.14 This could occur if, for example, some governments increase tax rates at the same time other governments reduce them. This could be the reason the (filtered) provincial tax rate series does not reject tax smoothing. To examine the tax smoothing hypothesis more carefully, tax rate data for each province will be examined. 
Data on taxes and output by province are available only since 1961, resulting in reduced sample size and power compared to the aggregate tests. Since the Cramer-von Mises statistic was earlier suggested to have high power even in small samples, it was estimated here for each province. Testing was undertaken with and without correction for the effect of time averaging from two tax rate changes per year. Results are shown in Table 3. In general, the results support those shown earlier. Only one province, Prince Edward Island, rejects the tax smoothing null hypothesis of white noise at the $5 \%$ level in the unadjusted test. After adjusting for the effect of time averaging, two provinces, Prince Edward Island and Nova Scotia, reject the white noise null hypothesis at the $5 \%$ level. 15

TABLE 3. Periodogram-Based Tests of White Noise by Province

\begin{tabular}{lll}
\hline Province 1962-1989 & First differenced tax rate & \\
\hline New & CVM & \\
Prince Edward Island & 0.17 & 0.26 \\
Nova Scotia & $0.47^{*}$ & $0.63^{*}$ \\
New Brunswick & 0.37 & $0.48^{*}$ \\
Quebec & 0.32 & 0.42 \\
Ontario & 0.23 & 0.06 \\
Manitoba & 0.06 & 0.08 \\
Saskatchewan & 0.02 & 0.09 \\
Alberta & 0.01 & 0.10 \\
British Columbia & 0.07 & 0.09 \\
5\% critical value & 0.21 & 0.31 \\
1\% critical value & 0.46 & 0.46 \\
\hline
\end{tabular}

NOTE: Variable examined is the first differenced average tax rate for each province. CVM denotes the estimated value of the Cramer-von Mises statistic. CVM is a scalar random cumulated periodogram statistic that tests for deviations in the estimated periodogram from the null hypothesis of white noise. $\mathrm{CVM}_{W}$ denotes the estimated value of the Cramer-von Mises statistic after correcting for time averaging. Correction for time averaging was made by filtering the first differenced tax rate series for the case of two tax rate changes per year, as described in Equation (9). See Appendix for data source.

*Significant at asymptotic $5 \%$ level. **Significant at asymptotic $1 \%$ level.

\section{CONCLUSION}

The tax-smoothing theory was examined at all levels of government in Canada and the U.S. Historical budget surplus data suggested that federal and provincial governments were tax smoothing, but state and local governments were not. Tax smoothing was examined by testing the null hypothesis of white noise in the first differenced tax rate series. Time series analysis in the frequency domain was undertaken by examining two cumulated periodogram statistics. Estimation was performed with and without correction for time averaging. At the federal levels, both average and marginal tax rates 
were examined. Average tax rates generally support tax smoothing by both federal governments and the Canadian provinces. The Canadian federal and provincial results were sensitive to adjustment for time averaging. Contrary to the federal and provincial results, tax smoothing was clearly rejected for state and local governments. The difference between federal and local governments was the strongest result found. In addition to average tax rates, "marginal tax rates" were examined at the federal levels. Marginal tax rate time series results generally reject tax smoothing for both federal governments.

The Canadian results were sensitive to adjustment for time averaging.

Regression tests were undertaken for federal average and marginal tax rates to examine the null hypothesis that tax rate changes are unpredictable. In general, regression tests could not reject the null hypothesis of tax smoothing in either country. Differences in resource mobility was suggested as an explanation for the tax smoothing differences between the states and provinces, and for greater tax smoothing by federal than by local governments.

\section{NOTES}

1. There are potential problems with Horrigan's test. First, Horrigan uses time trends to estimate trend real GNP and trend real government expenditures. If real output and real government expenditures are nonstationary, their regression on time may lead to spurious regressions. Second, Horrigan does not distinguish between current and capital debt. Such a distinction may be important for state and local governments, as resource mobility encourages these governments to finance capital expenditures with debt.

2. It is also interesting to note that until recently, with Canada's 1982 constitution, provinces were in some cases able to deny employment to workers from other provinces. The constitution now denies this except under more limited circumstances.

3. Although nearly every U.S. state has a balanced budget rule, this does not rule out tax smoothing. State governments could still smooth taxes by varying the size of their surpluses.

4. This author performed tests similar to those here, but omitting social insurance revenue. The results were identical to those reported here in terms of significance levels, and with little change in quantitative estimates. Results are available upon request.

5. Estimates of the marginal tax rate are not available for state/provincial and local governments.

6. The variance does not depend on the sample size and does not go to zero as the sample size increases.

7. Bernard and Durlauf (1990) provide evidence that the power of the Cramer-von Mises statistic is high, even in samples as small as 40 observations. For further discussion of these statistics as tests of the martingale hypothesis see Durlauf (1991).

8. First differences of averages composed from a set of random numbers will leave autocorrelations at lags higher than one unchanged. 
9. Major tax rate changes generally occur only once or twice a year in Canada and the U.S., at all levels of government (e.g., Firestone 1960; Pechman 1987; and Strick 1985).

10. See Hall (1988) and Haug (1991) for additional applications of the filter.

11. The partial correlations used in the filter can be calculated after knowing the theoretical correlation coefficient at lag one is 0.167 .

12. They are unable to reject the white noise null hypothesis for the period 1946-1986.

13. Strazicich (1996) performs regression tests for state and provincial governments using panel data. Results support tax smoothing by provincial governments, but reject tax smoothing by state governments.

14. This possibility was suggested by an anonymous referee.

15. Kolmogorov-Smirnov statistics were also estimated for each province, with and without correction for time averaging. None of the estimates reject the white noise null at the $5 \%$ level of significance. Results are available from the author upon request.

\section{REFERENCES}

Barro, Robert J. "On the Determination of the Public Debt." Journal of Political Economy 87 (1979): 940-71.

_. "On the Predictability of Tax-Rate Changes." Paper, University of Rochester, Rochester, New York, 1981.

"U.S. Deficits since World War I." Scandinavian Journal of Economics 88 (1986): 195-222.

Benjamin, Daniel K., and Levis A. Kochin. "A Theory of State and Local Government Debt." Paper, Department of Economics, University of Washington, Seattle, Wash., 1978.

Benjamin, Daniel K., and Levis A. Kochin. "A Proposition on Windfalls and Taxes when Some but not all Resources are Mobile." Economic Inquiry 20 (1982): 393-404.

Bernard, A. B., and Steven N. Durlauf. "Power Properties of Martingale Tests." Working Paper, Stanford University, Stanford, Ca., 1990.

Bizer, David S., and Steven N. Durlauf. "Testing the Positive Theory of Government Finance." Journal of Monetary Economics 26 (1990): 12341. 
Boskin, Michael J., and D. J. Puffert. "Social Security and the American Family." In Tax Policy and the Economy, edited by L. Summers. Cambridge: NBER and MIT Press, 1987.

Durlauf, Steven N. "Spectral Based Testing of the Martingale Hypothesis." Journal of Econometrics 50 (1991): 355-76.

Firestone, J. M. Federal Receipts and Expenditures during Business Cycles, 1879-1958. Princeton: Princeton University Press, 1960.

Gupta, Kanhaya L. "Optimal Taxation Policy: Evidence from Canada." Public Finance 47 (1992): 193-200.

Hall, Robert E. "Intertemporal Substitution in Consumption." Journal of Political Economy 96 (1988): 339-57.

Haug, Alfred A. "The Random Walk Hypothesis of Consumption and Time Aggregation." Journal of Macroeconomics 13 (1991): 691-700.

Hayashi, Fumio, and Christopher Sims. "Nearly Efficient Estimation of Time Series Models with Predetermined, but not Exogenous Instruments." Econometrica 51 (1983): 783-98.

Horrigan, Brian R. "The Determinants of the Public Debt in the United States, 1953-1978." Economic Inquiry (1986): 11-23.

Huang, Chao-Hsi, and Kenneth S. Lin. "Deficits, Government Expenditures, and Tax Smoothing in the United States: 1929-1988." Journal of Monetary Economics 31 (1993): 317-39.

Kochin, Levis A., Daniel K. Benjamin, and Mark Meador. "The Observational Equivalence of Rational and Irrational Consumers if Taxation is Efficient." In West Coast Federal Reserve/Academic Conference 1985.

San Francisco: Federal Reserve Bank of San Francisco, 1986.

Pechman, Joseph A. Federal Tax Policy, 5th ed. Washington, D.C.: The Brookings Institution, 1987.

Rea, S. A. Redistributive Effects of Canada's Public Pension Programs. Ottawa: Economic Council of Canada, 1981.

Sahasakul, Chaipat. "The U.S. Evidence on Optimal Taxation over Time." Journal of Monetary Economics 18 (1986): 251-75.

Strazicich, Mark C. "Are State and Provincial Governments Tax Smoothing? Evidence from Panel Data." Southern Economic Journal 62 (1996): 979_ 88.

Strick, J. C. Canadian Public Finance, 3d. ed. Toronto: Holt, Rinehart and Winston, 1985. 
Trehan, Bharat, and Carl Walsh. "Common Trends, the Government's Budget Constraint, and Revenue Smoothing." Journal of Economic Dynamics and Control 12 (1988): 425-44.

Working, Holbrook $\mathrm{H}$. "Note on the Correlation of First Differences of Averages in a Random Chain." Econometrica 28 (1960): 916-18.

\section{APPENDIX}

Data Definitions and Sources

Canada: Data comes from the CANSIM data base, Statistics Canada, and are part of the National Income and Expenditure Accounts of Canada, 1926-90.

\section{Federal}

Tax revenue is total revenue minus nontax revenue. Nontax revenue includes "interest on loans, advances and investments" to crown corporations, "remittances from government business enterprises," and "royalties" from natural resource ownership. Marginal tax rate data, 1947-84, comes from Gupta (1992).

Figure 1: Budget surplus is total revenue minus total expenditures. Figures include the Canada pension plan (CPP) surplus. The CPP was started in 1966.

\section{Provincial}

Tax revenue is total revenue minus nontax revenue. Nontax revenue is the same as for the federal government except that it also includes "profits from liquor commissions" and "transfers from the federal government." Quebec's tax revenue includes revenue from the Quebec Pension Plan (QPP).

Figure 2: Current budget surplus is total revenue minus total current spending. Current spending excludes spending on "fixed capital and inventories," but includes current depreciation of capital. Surplus excludes QPP surplus. The QPP started in 1966, and Quebec is the only province that does not participate in the national pension plan. Inclusion of the QPP surplus might distort the significance of the aggregate provincial government surplus figures and is therefore omitted from Figure 2.

\section{Local}

Tax revenue is total revenue minus nontax revenue. Nontax revenue includes "investment income" and "federal and provincial transfers."

Figure 3: Current budget surplus is total revenue minus total current spending, as described above.

United States: Data comes from the National Income and Product Accounts, 1982 edition, for the years 1929-82 and from the Survey of Current Business, various editions, 1983-90, unless otherwise noted. 


\section{Federal}

Tax revenue is total revenue minus nontax revenue. Nontax revenue includes various "fees, fines, donations, rents and royalties." Tax revenue includes social insurance revenue. Marginal tax rate data, 1938-82, comes from Sahasakul (1986).

Figure 1: Budget surplus is total revenue minus total spending, including the social insurance fund surplus.

State and Local

Tax revenue is total revenue minus nontax revenue. Nontax revenue is the same as for the federal government, except it also includes transfers from the federal government, or "Federal grants-in-aid."

Figures 2 and 3: Current budget surplus figures for state and local governments exclude capital spending on "structures." Figures are shown with and without the social insurance fund surplus. Data come from the Department of Commerce and are available upon request. 